\title{
Current Technique of the Arterial Switch Procedure for Transposition of the Great Arteries
}

\author{
EDWARD L. BOVE, M.D. \\ Section of Thoracic Surgery, C.S. Mott Children's Hospital, The University of Michigan \\ Medical Center, Ann Arbor, Michigan
}

\begin{abstract}
The arterial switch operation has recently become the preferred method of repair for patients with transposition of the great arteries in the majority of congenital heart centers. Concern regarding the late results in those patients undergoing atrial repairs has stimulated this major change in operative treatment. Although initially high, the current operative mortality has been reduced substantially to equal that of atrial repair in experienced institutions. The precise methods of coronary artery transfer, as well as aortic and pulmonary artery reconstruction have been refined to allow the routine performance of direct arterial repair within the first few weeks of life with low risk and excellent late survival. At the University of Michigan, a policy of arterial repair for all suitable infants with transposition of the great arteries with or without ventricular septal defect was adopted in July 1985. Although modifications in surgical technique have been made, the basic procedure has remained constant. This article reviews the current operative approach used in a consecutive series of 81 patients undergoing the arterial switch procedure.
\end{abstract}

The surgical treatment of patients with transposition of the great arteries has undergone a dramatic change with the recent addition of the arterial switch operation. First performed successfully by Jatene in $1976,{ }^{1}$ the indications, timing, and technique of this procedure have evolved to the point where routine arterial repair in the neonate is now performed with low mortality in a number of institutions. Important contributions by many surgeons have led to a gradual evolution of techniques resulting not only in improved survival but in reduced postoperative hemodynamic residua. ${ }^{2-9}$ Refinements in the methods of coronary artery transfer and pulmonary artery reconstruction have significantly lowered early and late morbidity. ${ }^{10-12}$ This article focuses on the

Address for correspondence: Dr. Edward L. Bove, University of Michigan Hospitals, 1500 East Medical Center Drive, 2120 Taubman Center, Box 0344, Ann Arbor, MI 48109. technique of arterial repair as currently used at The University of Michigan.

\section{INDICATIONS}

Patients with transposition of the great arteries (ventriculoarterial discordance) are initially evaluated with echocardiography to determine their suitability for arterial repair. All patients with atrioventricular concordance and balanced ventricular size are considered acceptable candidates with the exception of those having significant, fixed pulmonary stenosis (left ventricular outflow tract obstruction). Cardiac catheterization and balloon atrial septostomy are generally performed and prostaglandin infusions (if needed prior to septostomy) are weaned. Infants with intact ventricular septum undergo repair within the first week of life while those with large ventricular septal defects may be delayed until 3 to 4 weeks 
of age. No particular effort is made to define the coronary anatomy as all anatomic variants are considered suitable for direct arterial repair.

\section{TECHNIQUE OF REPAIR}

The heart is approached through a standard median sternotomy. A large section of pericardium is harvested and placed in a $0.6 \%$ glutaraldehyde solution for 6 to 8 minutes in order to improve its handling characteristics. The anatomy is inspected carefully with particular note made of the coronary artery distribution and the great vessel relationships. Mobilization of the aorta and pulmonary artery is then performed, skeletonizing the aorta to the level of the innominate artery. The pulmonary arteries must be extensively mobilized into each hilum, circumferentially freeing the right and left branches beyond the pericardial reflections until the upper lobe vessels are identified. This maneuver is necessary in order to prevent tension on the pulmonary artery suture line when it assumes its new anterior location. The ductus arteriosus is encircled with a heavy braided silk suture for subsequent ligation and division after the establishment of cardiopulmonary bypass.

The repair is performed using deep hypothermic $\left(20^{\circ} \mathrm{C}\right)$ bypass and reduced flow (Fig. 1). Rare exceptions are made for patients of extremely small size $(<2 \mathrm{~kg})$ and those with anomalies of systemic venous return. In these situations, a single venous cannula is placed in the right atrial appendage and the repair is carried out under circulatory arrest. The arterial cannula (10 F THI, Sherwood Medical, St. Louis, MO, USA) is placed in the aorta at the level of the innominate artery. Bicaval venous cannulation (12 F, DLP, Grand Rapids, MI, USA) is accomplished with pursestring sutures placed directly in each vena cava. Monofilament suture is preferred for the superior vena cava pursestring in order to allow nontraumatic removal and direct repair of the vena cava at the completion of the procedure to prevent narrowing. As bypass is begun, the ductus is divided and each end is ligated or oversewn. The heart is vented via the right superior pulmonary vein. The flow is then reduced to 0.6 $\mathrm{L} / \mathrm{min} / \mathrm{m}^{2}$ and the aorta cross-clamped. A dilute blood cardioplegic solution ( $30 \mathrm{~mL} / \mathrm{kg}$ ) is ad-

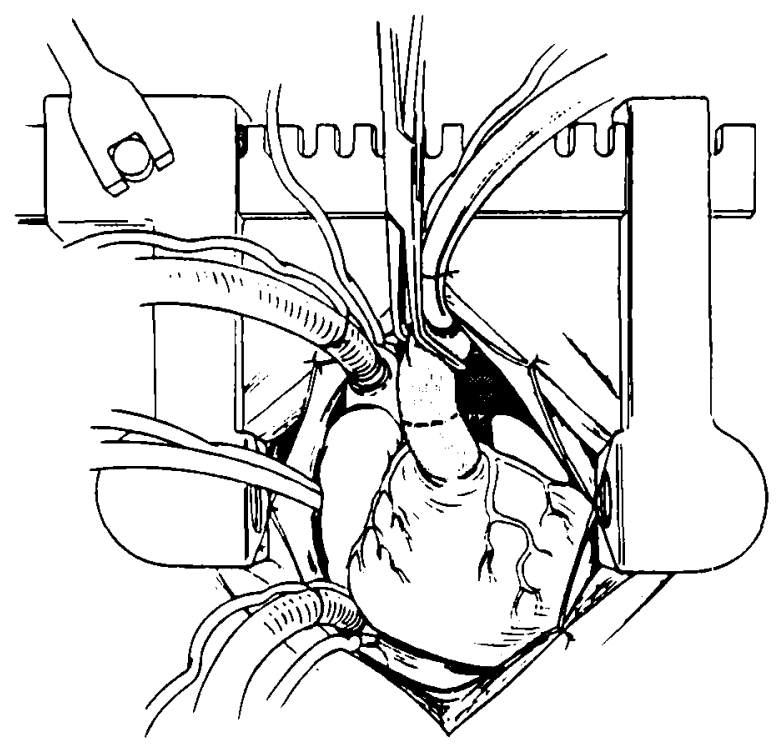

Figure 1. The appearance of the heart after establishing cardiopulmonary bypass is shown. Superior and inferior vena cava, and left atrial cannulas are in position. The ductus arteriosus is divided. The proposed levels of great vessel transection are marked (dotted lines).

ministered and topical cooling is added.

Atrial and ventricular septal defects are repaired first. Without exception, all ventricular septal defects have been patched through the tricuspid valve. The atrial septal defects have also been closed with a patch in the majority of patients, particularly when the septum has been extensively torn from a previous balloon septostomy.

Attention is then directed to transection of the great vessels (Fig. 2). The level of the pulmonary artery bifurcation is noted and the aorta is transected approximately $5 \mathrm{~mm}$ distal to that point. The pulmonary artery is then cut right at its bifurcation. This allows as long a length as possible for the neoaortic root, keeping the suture line away from the valve and coronary arteries. Once the vessels are transected, further mobilization of the posterior aspect of the left pulmonary artery can then be accomplished if necessary. The coronary ostia are inspected at this time and their proximity to the valve attachments are noted. Occasionally, the ostia may be extremely close to the posterior commissure, making removal difficult. The morphology of the neoaortic valve is inspected, and the point where the superior margin of each commissure attaches to the vessel wall is marked with a suture exteriorly. 


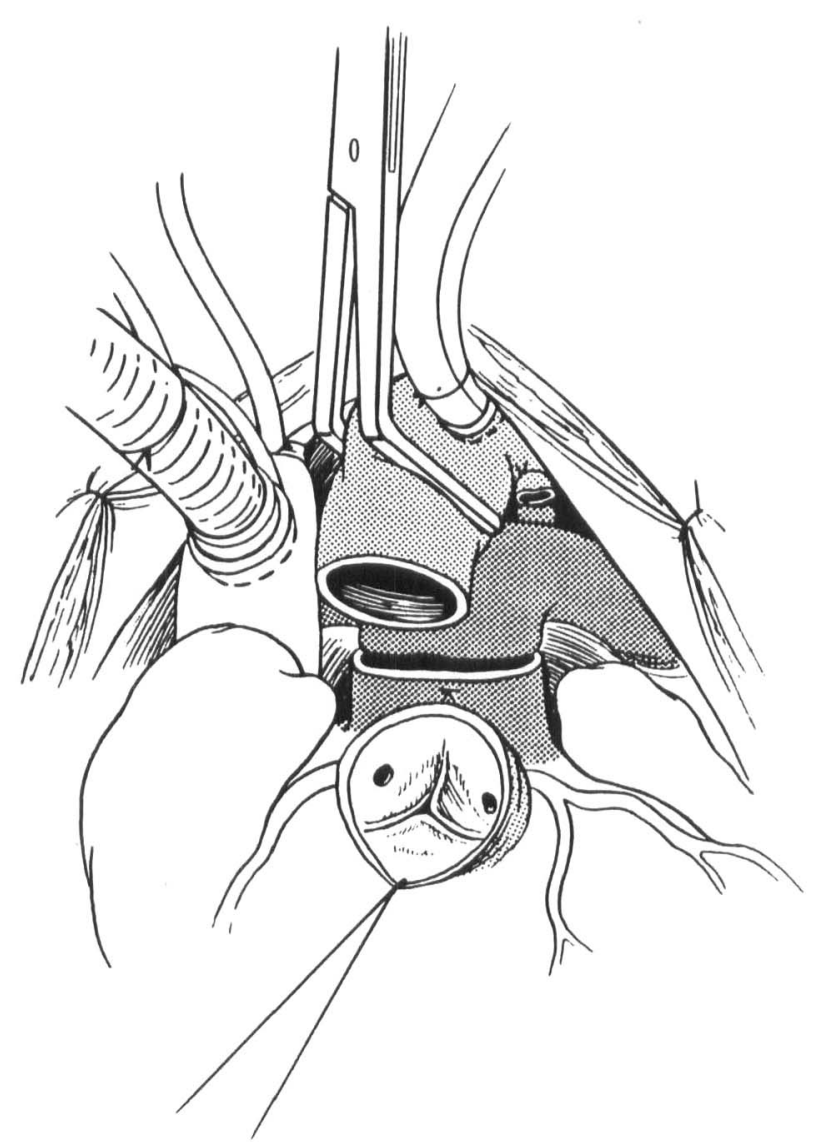

Figure 2. The aorta and pulmonary artery are divided and the proximal aorta held with a stay suture demonstrating the coronary artery orifices. A marking suture identifies the superior extent of the anterior commissure of the pulmonary (neo-aortic) valve.

The distal aorta is then relocated posterior to the pulmonary artery bifurcation (LeCompte maneuver) and anastomosed to the proximal pulmonary artery (Figs. 3 and 4). A simple running 7-0 monofilament technique is now preferred. A size discrepancy between the smaller distal aorta and the larger proximal pulmonary artery is invariably present. When this difference is small, simple tailoring of the anastomosis is all that is needed. Often, a few millimeter cut back into the anterior aorta will be required. On rare occasions, a triangular section of pericardium must be inserted into the anterior half of the anastomosis when the size discrepancy is extreme. The LeCompte maneuver is not utilized when the great vessels are in a side-by-side position in order to prevent tenting of the left pulmonary artery. Follow-

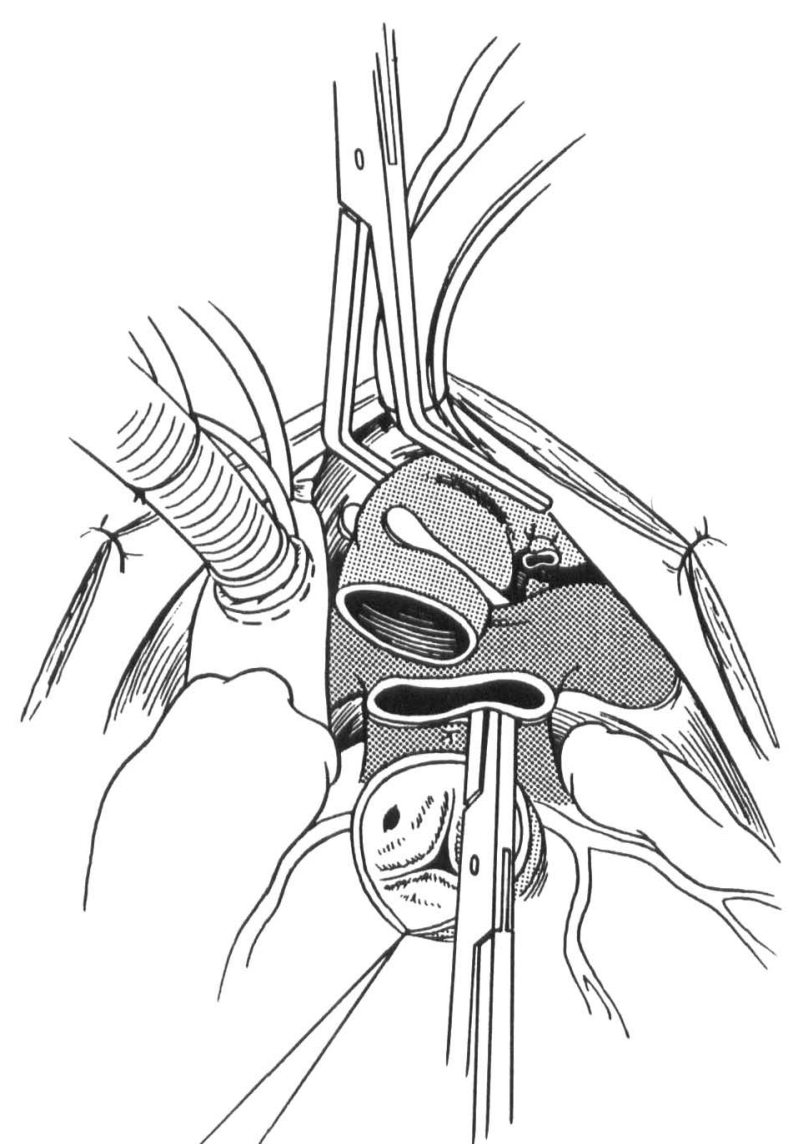

Figure 3. The distal aorta is grasped with a right-angle clamp and repositioned posterior to the pulmonary artery bifurcation.

ing completion of this anastomosis, the crossclamp is removed to inspect the suture line and additional sutures can be placed as necessary (Fig. 5).

Excision of the coronary arteries is then done, beginning with the left coronary artery (Fig. 6). The entire sinus of Valsalva tissue is removed to within 1 to $2 \mathrm{~mm}$ of the valve attachment. After the coronary artery is excised, slight mobilization of the vessel can be done as is necessary to achieve a tension-free anastomosis. When the aorta is slightly to the right of the pulmonary artery, little or no mobilization of the left coronary artery is needed, although 5 to $7 \mathrm{~mm}$ of additional length is usually required on the right coronary artery as it must reach behind the neopulmonary root. Removal of the aortic cross-clamp, allowing the neo-aorta to distend and assume its natural posi- 


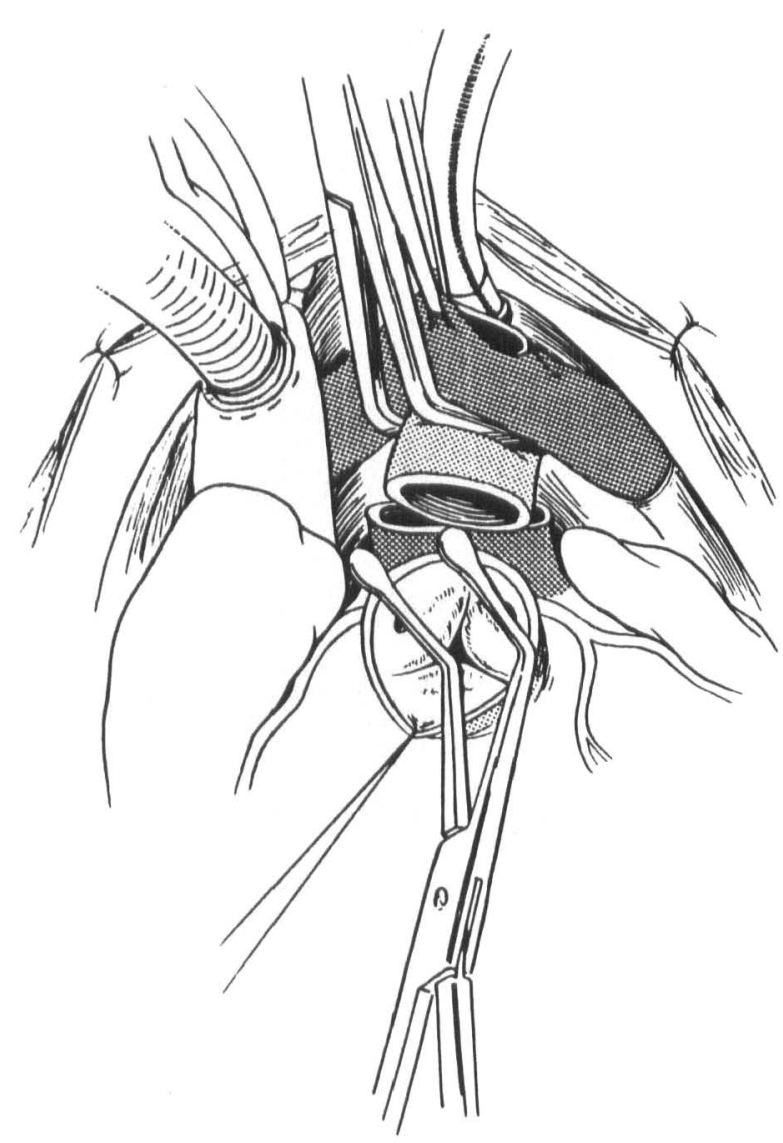

Figure 4. The new position of the distal aorta behind the pulmonary artery bifurcation is shown.

tion greatly facilitates identifying the new location of each coronary anastomosis (Fig. 7). Oblique incisions are made in each facing sinus of the neoaortic root without removing any tissue. The aortic cross-clamp is left off until the incision is begun, closing the valve and protecting it from injury. The previously placed marking sutures also serve as a guide to the location of the valve commissures. The coronary arteries are held next to the openings in the neo-aorta in a tension-free position to be certain that no twist occurs during the anastomosis. When the circumflex coronary artery originates from the right, a slight counterclockwise twist $\left(10^{\circ}\right.$ to $\left.15^{\circ}\right)$, reimplanting the vessel slightly more distally, is necessary to prevent kinking of the circumflex artery.

Reconstruction of the neo-pulmonary artery is begun by repairing the defects left after coronary artery excision (Fig. 8). A large pantaloon-shaped patch of autologous pericardium is now preferred

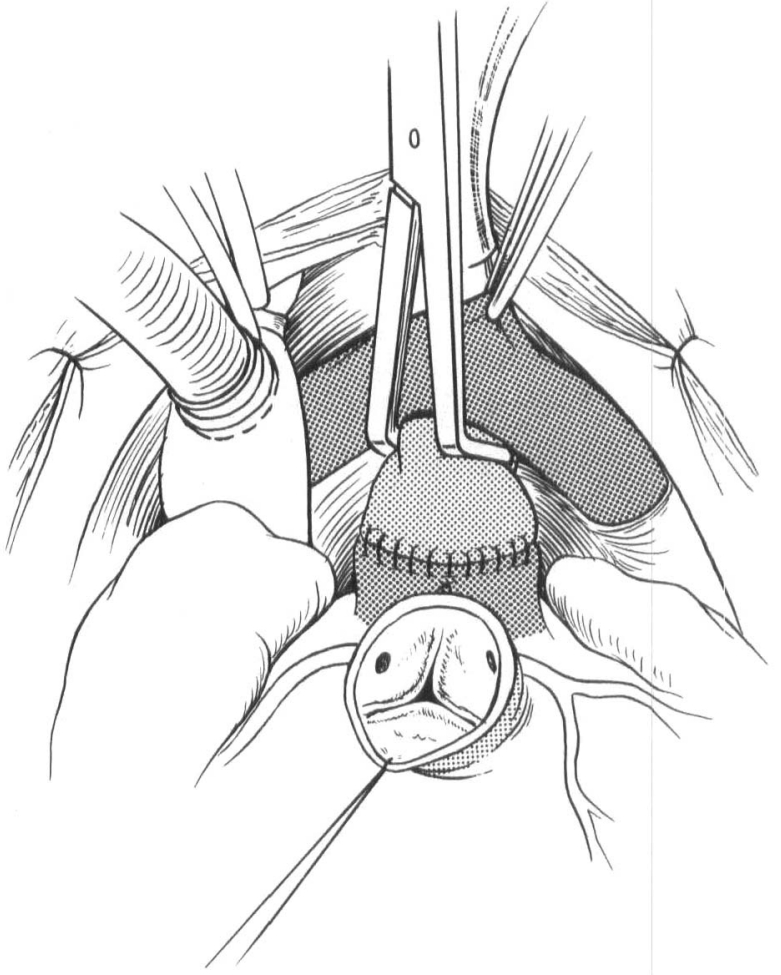

Figure 5. The anastomosis between the distal aorta and proximal pulmonary artery is completed. The clamp is released to examine for hemostasis along the suture line.

as this provides adequate tissue for the sinuses of Valsalva as well as augmenting the entire anastomotic circumference. The aortic crossclamp is generally removed during this portion of the operation and systemic rewarming is begun, allowing careful inspection of both coronary suture lines. A left atrial monitoring catheter is inserted and bypass is discontinued in the usual fashion.

\section{POSTOPERATIVE MANAGEMENT}

All patients are routinely ventilated for a minimum of 24 hours. Nearly all patients have required some inotropic support, particularly those with intact ventricular septum undergoing repair beyond 2 weeks of age. Isoproterenol infusions have generally been used (0.02 to $0.1 \mu \mathrm{g} / \mathrm{kg} / \mathrm{min})$. This agent provides a strong positive inotropic effect in addition to decreasing systemic vascular resistance and increasing heart rate, all beneficial actions in the postoperative arterial switch patient. Heart rate may be allowed to increase up to 200 beats/min if low cardiac output is significant. In- 


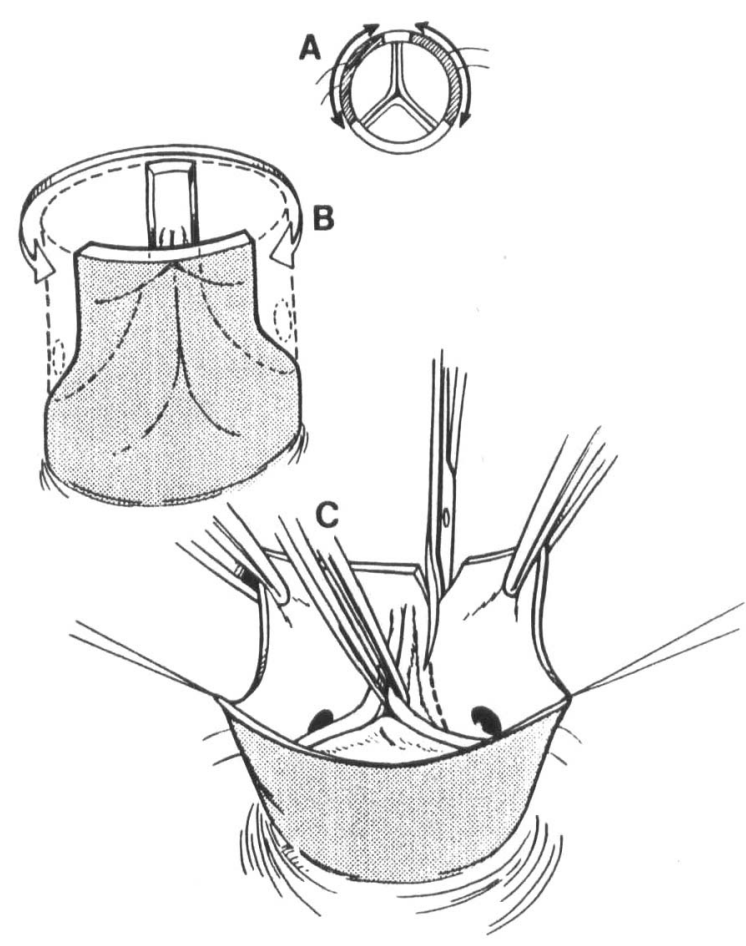

Figure 6. Adequate excision of the coronary arteries requires removal of a wide button of arterial wall essentially amounting to $2 / 3$ of the neopulmonary arterial circumference and extending to within 1 to $2 \mathrm{~mm}$ of the valve attachment $(A, B)$. Traction on the valve leaflet facilitates coronary artery excision (C).

fants within the first 2 weeks of life have rarely required more than minimal support. Low cardiac output should be investigated with an electrocardiogram to search for ST and T wave evidence of myocardial ischemia. In addition, a Doppler/ echocardiogram may be obtained to assess valve stenosis or regurgitation, anastomotic obstruction, residual shunting and ventricular function. Invariably, any diffuse ventricular dysfunction secondary to a poorly prepared left ventricle has completely resolved by 48 to 72 hours following repair.

\section{RESULTS}

The arterial switch procedure for transposition of the great arteries has been performed in $81 \mathrm{pa}$ tients. The overall operative mortality for the entire series has been 5 patients $(5 / 81,6 \%)$. The series includes 20 patients with hemodynamically significant ventricular septal defects including those with double outlet right ventricle ( 2 deaths,

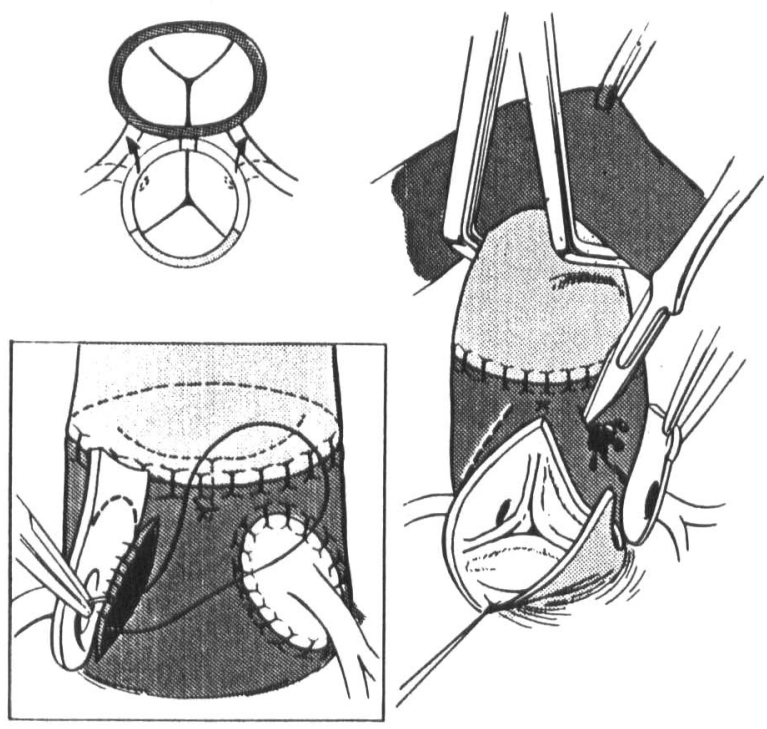

Figure 7. The left coronary artery is reimplanted after an oblique incision is made in the left anterior sinus of Valsalva of the neo-aorta. The cross-clamp is removed during the incision to close the neo-aortic valve and protect it from injury. The same procedure is repeated for the right coronary artery (inset). The actual distance traveled by each coronary artery is small, requiring little mobilization of the vessels (upper left).

$10 \%)$ and 61 patients with intact ventricular septum ( 3 deaths, 5\%). Increasing experience has led to a reduction in the operative risk, with only 1 death in the last 56 consecutive repairs (1/56, 2\%).

All patients have undergone detailed postoperative Doppler/echocardiogram evaluations. ${ }^{13}$ No patient has significant left ventricular outflow tract obstruction. Only 4 patients had mild obstruction by Doppler examination, the highest gradient noted was $29 \mathrm{mmHg}$. This patient was catheterized and no gradient was found. However, mild supravalvar pulmonary stenosis was found relatively often. Significant gradients requiring reoperation were noted in 5 patients, all undergoing repair early in the series. Since adopting the current technique of pulmonary artery reconstruction with a large autologous pericardial patch, there have been no instances of more than mild right ventricular outflow tract gradients. Aortic regurgitation was noted in 5 patients, all mild. This regurgitation was often clinically undetectable and has not progressed in any patient. All patients have had normal left ventricular systolic function as measured by M-mode echocardiography. In 


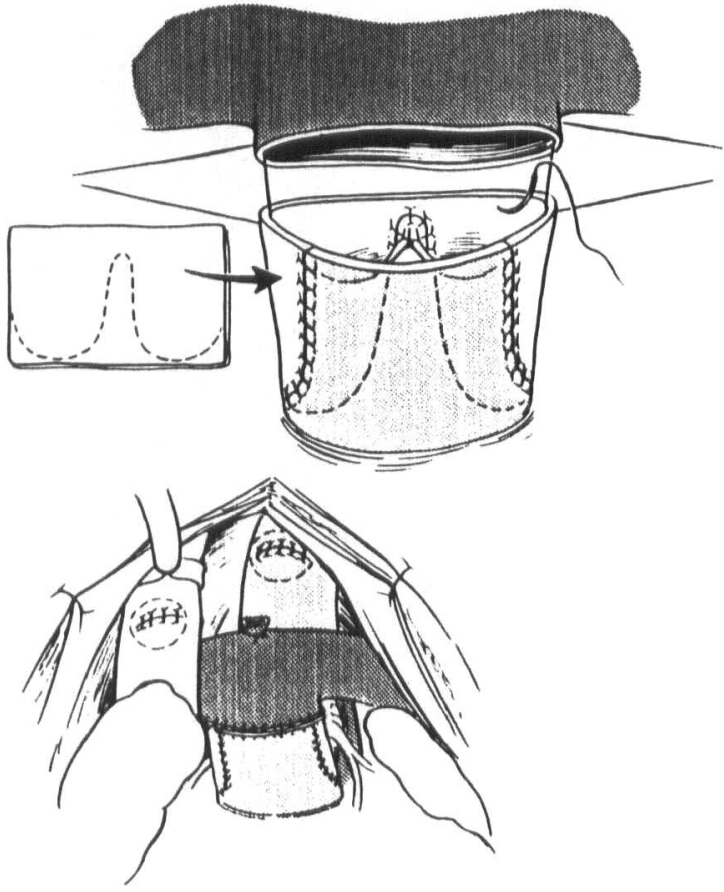

Figure 8. A large rectangular pericardial patch previously placed in $0.6 \%$ glutaraldehyde for 6.8 minutes is trimm$\theta d(A)$ and sutured into the neopulmonary root to rebuild the defects resulting from coronary artery excision. The anastomosis to the distal pulmonary artery bifurcation is completed.

addition, normal right and left ventricular wall motion was noted in all patients by two-dimensional echocardiography. Normal sinus rhythm is present in all patients and no patient has ischemic ECG changes.

\section{COMMENT}

At the University of Michigan, the arterial switch operation has been used as the procedure of choice for all suitable patients with transposition of the great arteries since July 1985. Although some modifications of the technique have been made with increasing experience, the operative approach remains basically unchanged. The greatest modifications have involved reconstruction of the pulmonary artery. Early in our experience, supravalvar pulmonary stenosis occurred relatively often. Although usually mild, a few patients required reoperation for severe obstruction. The reasons included insufficient mobilization of the branch pulmonary arteries, failure to adequately augment the coronary artery excision sites and relative hypoplasia of the neopulmonary annulus. In the normal heart, the pulmonary valve annulus is 1 to $2 \mathrm{~mm}$ larger than the aortic valve annulus. ${ }^{14}$ Following the arterial switch procedure, therefore, the neopulmonary root is slightly smaller than normal and may contribute to outflow tract obstruction. Enlargement of the suture line with a pantaloon-shaped pericardial patch and extensive mobilization of the distal pulmonary arteries has virtually eliminated the problem of supravalvar pulmonary stenosis. To date, this technique has resulted in no instances of significant left ventricular outflow tract obstruction, aortic regurgitation or coronary insufficiency.

The majority of institutions in this country are now using the arterial switch operation for infants with transposition of the great arteries. Survival now equals and even exceeds that for atrial repairs in experienced centers. ${ }^{15,16}$ Late follow-up studies will continue to be important in assessing the arterial repair as a truly corrective operation for transposition of the great arteries.

\section{REFERENCES}

1. Jatene AD, Fontes VF, Paulista PP, et al: Anatomic correction of transposition of the great vessels. J Thorac Cardiovasc Surg 72:364, 1976.

2. Pacifico AD, Stewart RW, Bargeron LM Jr: Repair of transposition of the great arteries with ventricular septal defect by an arterial switch operation. Circulation 68:II, 1983.

3. Castaneda AR, Norwood WI, Jonas RA, t at: Transposition of the great arteries and intact ventricular septum: Anatomical repair in the neonate. Ann Thorac Surg 38:438, 1984.

4. Bical O, Hazan E, LoCompte Y, et al: Anatomic correction of transposition of the great arteries associated with ventricular septal defect: Midterm results in 50 patients. Circulation 70:891, 1984.

5. Quaegebeur JM, Rohmer J, Ottenkamp J, et al: The arterial switch operation: An eight-year experience. J Thorac Cardiovasc Surg 92:361, 1986.

6. Bove EL, Byrum CJ, Kavey RW, et al: Arterial repair for simple and complex forms of transposition of the great arteries. J Thorac Cardiovasc Surg 28:54, 1987.

7. Idriss FS, Ilbawi MN, DeLeon SY, et al: Arterial switch in simple and complex transposition of the great arteries. J Thorac Cardiovasc Surg 95:29, 1988.

8. Brawn WJ, Mee RBB: Early results for anatomic correction of transposition of the great arteries and 
for double-outlet right ventricle with subpulmonary ventricular septal defect. J Thorac Cardiovasc Surg 95:230, 1988.

9. Bove EL, Beekman RH, Snider AR, et al: Arterial repair for transposition of the great arteries and large ventricular septal defect in early infancy. Circulation 78:III, 1988.

10. Yacoub MH, Radley-Smith R: Anatomy of the coronary arteries in transposition of the great arteries and methods for their transfer in anatomical correction. Thorax 33:418, 1978.

11. LeCompte $Y$, Zannini L, Hazan E, et al: Anatomic correction of transposition of the great arteries. $J$ Thorac Cardiovasc Surg 82:629, 1981.

12. Paillole $C$, Sidi $D$, Kachaner $J$, et al: Fate of pulmonary artery after anatomic correction of simple transposition of great arteries in newborn in- fants. Circulation 78:870, 1988.

13. Martin MM, Snider AR, Bove EL, et al: Twodimensional and Doppler echocardiographic evaluation after arterial switch repair in infancy for complete transposition of the great arteries. Am J Card 63:332, 1989.

14. Rowlatt UF, Rimoldi HJA, Lev M: The quantitative anatomy of the normal child's heart. Pediat Clin North Am 10:499, 1963.

15. Castaneda AR, Trusler GA, Paul MH, et al: The early results of treatment of simple transposition in the current era. J Thorac Cardiovasc Surg 95:14, 1988.

16. Norwood WI, Dobell AR, Freed MD, et al: Intermediate results of the arterial switch repair. $J$ Thorac Cardiovasc Surg 96:854, 1988. 